\title{
SOBRE ELS TERRATRÈMOLS DELS ANYS 1427 I 1428 A CATALUNYA
}

Alexandre Olivar

En un full de pergami enganxat a l'interior de la tapa posterior, de fusta, del manuscrit 988 de la Biblioteca del monestir de Montserrat' llegim, escrita amb lletra del segle xv, la següent nota sense títol:

Fou feta en Cathalunya gran terra tremol en lany M CCCC XVII, e comensa lo vespre del diumenge deles falles lo disapte anit, e dura dos anys continus, e sovint feyt (?) grans terra tremols specialment lo die de nostra dona de febrer de mati ales VIII hores, e caygueren molts hedificis specialment vna vidriera ho / o / de sancta maria dela mar en que moriren XXXXII persones.

He posat un interrogant després de «feyt», perquè la paraula no es deixa llegir bé a causa d'una corcadura.

La nota no representa una informació històrica de fets desconeguts, però pels detalls que aplega i per certes precisions que fa mereixia de ser transcrita i estudiada. Els terratrèmols que afectaren la part nord-oriental de Catalunya durant la primera

1 Vegeu la descripció del conjunt d'aquest còdex a A. Ouvar, "Catàleg dels manuscrits de la Biblioteca del Monestir de Montserrat", Scripta et Documenta 25, Monestir de Montserrat 1977, pp. 294-295. 
meitat del segle XV són prou coneguts. Estem particularment ben informats dels de la sèrie olotina que van de l'any 1410 al 1430 . El 1427 fou un any molt afectat en aquest sentit, sobretot de febrer a maig, però els terratrèmols es repetiren el mateix dia de Nadal i continuaren, encara que amb menys freqüència, però no amb menor intensitat, durant l'any 1428, d'una manera especial el dia 2 de febrer. Les terres afectades foren, que sapiguem, les d'Olot, naturalment, però també altres de l'actual província de Girona, Montpeller i particularment la ciutat de Barcelona; almenys les notícies que dels efectes dels terratrèmols ens forneixen els documents barcelonins són abundants i riques en detalls ${ }^{2}$. El testimoni que hem transcrit és igualment barceloni, ja que ho és tot el còdex a què pertany ${ }^{3}$.

Si analitzem el nostre testimoni segons l'ordre del text, hem de començar per dir que ja hem vist l'envergadura geogràfica que té l'expressió «en Cathalunya», segons les notícies conservades ${ }^{4}$. Que els terratrèmols (cal entendre-ho sempre en plural) dels anys 1427 i 1428 foren grans (la segona vegada el nostre text diu "grans terra tremols») queda explicat pels efectes que el mateix testimoni enumerarà després. De fet, també fora de Barcelona, els estralls foren considerables.

El nostre document està d'acord amb els altres testimonis en dir que la famosa sèrie de terratrèmols que ens ocupa començà «el diumenge deles falles». L'expressió ha de ser entesa com del diumenge de Quinquagèsima, o sigui, de carnestoltes, dit tam-

${ }^{2}$ La documentació ha estat curiosament aplegada per E. FonTsERE i J. Iglésies, Recopilació de dades sísmiques de les terres catalanes entre $1100 i$ 1906, Barcelona 1971, pp. 125-192.

${ }^{3}$ Al foli CXXXXVI llegim: «Explicit uiridarium consolationis. Scriptor autem fuit Petrus Auinyo beneficiatus in sede barcinonensi». El nom de Pere Avinyó no apareix en el gran inventari de Colophons dels Bénédictins du Bouveret. Pere acabà la seva transcripció el 5 de gener del 1482 (cf. Olivar, 295). El ms. 988 de Montserrat ha de ser afegit al repertori de manuscrits datats de A. Millares Carlo i J.M. Ruiz Asencio, Tralado de paleografía española, 3a. edició, I, Madrid 1983, p. 396.

${ }^{4}$ En graus menors aquests moviments sísmics es deixaren percebre a la meitat sud de Catalunya $\mathrm{i}$ més enllà de les seves fronteres, peninsula endins. Cf. Fontsere-Iglésies, p. 189. 
bé, en altres temps, diumenge fallar ${ }^{5}$, és a dir, de les falles. Era el 2 de març del 1427. Un manual de l'església de Santa Coloma de Queralt informa: «Ha III dies de carnestoltes M.CCC.XXVII comença la terra tremol e dura tot l'any; de temps en temps ne feya» ${ }^{6}$. A tres dies de carnestoltes, o sigui, el tercer dia abans del Dimecres de Cendra, és a dir, el diumenge susdit. El «vespre» del diumenge diu el nostre document: «poc apres que hagueren tocades les nou hores de la nit», diuen les Rúbriques de Bruniquer"; «en la nit seguent pus prop a aquest diumenge poch apres que hagueren tocades IX hores"), segons el Manual de Novells Ardits"; «vers les nou hores», segons el Llibre de les Solemnitats de l'Arxiu Municipal de Barcelona ${ }^{9}$. «Lo disapte anit» és una precisió donada pel document conservat a Montserrat que només trobo confirmada pel Dietari de la Diputació, el qual anota, sense concretar l'hora, que els terratrèmols van començar el dissabte dia primer de març ${ }^{10}$.

«E dura dos anys continus... specialment lo die de nostra dona de febrer». Això ens porta al dia de la Purificació de la Mare de Déu, 2 de febrer del 1428. Que aquest dia marca el paroxisme d'aquell període sísmic és atestat per nombrosos testimonis. La tribulació a Barcelona, i a Catalunya", fou gran aquell dia, $i$ els perjudicis materials, enormes. Hom ha assignat per als terratrèmols de les terres olotines d'aquell dia els graus IX-X, per a Barcelona el VIII ${ }^{12}$. En aquesta ocasió s'esfondrà la volta principal de la basílica de Ripoll i part del claustre i del

5 Diccionari Aguilo, IV, 15: «fallà».

${ }^{6}$ Fontseré-Iglesies, op. cit., p. 168, En la reproducció de textos antics ja editats $m$ 'he permès, alguna vegada, fer certes correccions que m'han semblat lícites per acostar més el text a l'original. Noteu que terratrèmol, escrit també terra tremol, apareix en masculi i, potser més sovint, en femeni, en el nostre text $\mathrm{i}$ els documents consultats; cf. Diccionari Alcover, X, 259.

7 Fontseré-Iglésies, op. cit, p. 125.

8 Ibid.

${ }^{9}$ Fontseré-Iglésies, op. cit., p. 126.

10 Fontsere-Iglesies, op. cit., p. 125.

11 Vegeu el gràfic de Fontseré-Iglésies, op. cit., p. 164.

12 Fontseré-Iglésies, op. cit., p. 163. 
cenobi $^{13}$, i sofriren greus danys altres edificis monàstics, com Sant Joan de les Abadesses, Sant Esteve de Banyoles i Santa Maria d'Amer, per no parlar d'edificacions menors $i$ de viles ${ }^{14}$. Els morts foren nombrosos. «A les VIII hores» és una precisió cronològica confirmada pel Llibre de les Solemnitats: «A la jornada o festa de la purificacio de nostra dona sancta maria del mes de febrer, en la qual jornada vers les VIII hores del mati feu una gran percudida de terratremol ${ }^{15}$. També el Manual de Novells Ardits indica la mateixa hora: "Ffeste de la purificacio de la verge maria. Aquest dia segons plague a nostre senyor deu vers les VIII hores ans de mig jorn fou molt gran e spaventable terra tremolt de gran durada» etc. ${ }^{16}$.

«E caygueren molts hedificis»: les fonts són molt unànimes en declarar que s'enderrocaren o quedaren malparats molts castells i altres edificis, sobretot els alts, com és natural ${ }^{17}$. Molts dels edificis que no caigueren totalment hagueren de ser demolits o almenys apuntalats.

«Specialment vna vidriera ho / o / de sancta maria dela mar». El cas de Santa Maria del Mar és esmentat generalment per les fonts històriques, no solament per la magnitud del dany que sofrí el grandiós edifici, sinó pel nombre de víctimes que tingué, com veurem. La rosassa de Santa Maria del Mar rep aquí el nom de o. O és una denominació comuna de rosassa, o sigui, d'una obertura calada i vidrada, de forma circular. En referir-se al mateix rosetó de Santa Maria del Mar els documents adduïts diuen també $\mathrm{o}^{18}$. Curiosament, el nostre document dóna la doble grafia en què apareix el terme: ho $\mathrm{i}^{19}$, juxtaposant les dues formes,

13 Fontsere-Iglesies, op. cit., p. 169 (font: Jeroni Pujades, Flosculi) i 192 (font: J.M. Pellicer i Pagès, el qual dóna erròniament l'any 1429).

14 Fontseré-lgitesies, op. cit., p. 171.

15 Fontsere-lglesies, op. cil., p. 166.

16 Manual de Novells Ardits vulgarment apellat Dietari del Antich Consell Barceloni, I, Barcelona 1892, p. 258.

17 Fontsere-lglesies, op. cil., pp. 165 ss.

${ }^{18}$ Fontsere-Iglésies, op. cit., p. 165, Bruniquer, 166, Novells Ardits, Solemnitats, Generalitat 642, 168 (testament de Santa Coloma de Queralt).

19 La grafia ho, en el Dielari del Capellà d'Alfons el Magnànim: FonTseréIglésies, op. cit., p. 183, també es refereix a Santa Maria del Mar. 
tal com ho hem transcrit. O, per designar una rosassa, fou un nom d'ús corrent a Catalunya fins al final del segle Xvi, almenys ${ }^{20}$. Hom parlava ordinàriament de la o de Santa Maria del $\mathrm{Pi}$, de Barcelona; ho diuen encara? ${ }^{21}$.

Així doncs el nostre text recorda, entre els molts accidents ocorreguts aquell dos de febrer, com a especialment memorable, la caiguda de la o de Santa Maria del Mar, una rosassa enorme, la qual fou reconstruida l'any 1459.

El nombre precís de quaranta-dues víctimes, mortes per la caiguda de la rosassa, és una xifra curiosa, perquè no està en consonància amb cap altre document, dels que han arribat al meu coneixement. «Be XX persones», tal com diu el manual de Santa Coloma de Queralt ${ }^{22}$ és la quantitat més baixa de les que coneixem; l'expressió, pròpia d'un testimoni allunyat del lloc de l'esdeveniment, és imprecisa. Vint-i-una o vint-i-dues persones «entre homens, dones e infants", diu el Manual de Novells Ardits ${ }^{23}$. "Cecidit lo o ecclesie beate Marie de Mari et occidit viginti duas personas", llegim en el Llibre Verd menor de Perpinyà ${ }^{24}$, testimoni llunyà i que depèn, sens dubte, de la mateixa font dels testimonis anteriors. «Morirenhi be 25 persones», diuen les Rúbriques de Bruniquer ${ }^{25}$ i el Llibre de les Solemnitats ${ }^{26}$, els quals sembla que arrodoneixen la xifra. En el document Generalitat 642 de l'Arxiu de la Corona d'Aragó, quan informa que en la caiguda de la o de Santa Maria de la Mar (observem, de pas, que el nom tradicional de la famosa església gòtica barcelonina és així: de la Mar, segons els documents) «moriren XV persones ${ }^{27}$, hem de veure-hi, probablement, un error del copista, el

${ }^{20}$ Diccionari Alcover, VII, p. 823.

21 Vegeu el Diccionari Aguiló, V, p. 224. Els diccionaris catalans moderns no registren aquest mot, potser perquè el deuen considerar en desús.

${ }^{22}$ Fontseré-Iglésies, op. cit., p. 168.

23 Fontseré-Iglesies, op. cit., p. 166.

${ }^{24}$ FonTSERE-Iolesies, op. cit., p. 179. En aquest text cal llegir ecclesie i no ecclesia; noteu-hi l'expressió no llatinitzada lo o, en masculi.

${ }^{25}$ FontSeré-Iglésies, op. cit., p. 165.

${ }^{26}$ Fontseré-Iglésies, op. cit., p. 166.

${ }^{27}$ Ibid. 
qual escriví XV en lloc de XXV. Hi ha altres documents que s'acosten més a la quantitat assenyalada pel nostre testimoni, superant-la però; així, en el preàmbul d'un testament atorgat el 1430 a Santa Coloma de Queralt llegim que «moriren ben L persones o mes" ${ }^{28}$. També aquesta indicació és força imprecisa, com ho són dos testimonis gironins, menys fonamentats encara, els quals parlen de cinquanta persones ${ }^{29}$. Cinquanta és manifestament una quantitat que vol ser aproximada.

L'esmentat testament de Santa Coloma de Queralt és l'única font que proporciona detalls de com anà l'accident; hi llegim: «Per la terra tremol que feye gran queyen les lochs, e les torres, e los castells, specialment en lo jorn de nostra dona sancta Maria Caneler que lo feu tant fort e tant gran que a Barcelona a sancta Maria de la mar caygue una o de la obra hon moriren ben L persones o mes ala porta de esglesia, car era tot hom per beneyr les candeles $)^{30}$. En parlar, a continuació immediata, del que passà en aquella ocasió a Puigcerdà, diu: «Hoch no res menys aquest dia metex a Puigcerda caygue a preicado(r)s o a frameno(r)s lasglesia mentre deien la missa, hon moriren pus de $\mathrm{C}$ persones entre frares e capelans e homs e dones que eren ala dita esglesia per oir missa novella». Dir «pus de C persones» és igualment, amb prou evidència, donar una xifra aproximada $\mathrm{i}$ arrodonida. És probable que l'autor s'imagini també com van succeir els accidents mortals. És, però, més versemblant que la gent, aplegada a les vuit del mati, hora ordinària de la celebració de la missa, especialment concorreguda amb motiu de la benedicció de les candeles, en notar el terratrèmol es precipités cap a les portes de l'església; molts dels qui ho feren vers la porta frontal foren victimes de les peces del calat de la rosassa que es desprengueren i caigueren, més aviat a la part interna del temple que no a l'externa, aquesta més protegida verticalment per l'arquitectura. El Llibre de les Solemnitats ho descriu aixi: «E mes

28 Fontsere-Iglesies, op. cit., p. 168.

29 FontSERE-Iglésies, $o p$, cit., p. 184 s. (Es tracta d'autors que no citen les fonts que han utilitzat, si és que n'han utilitzades).

${ }^{30}$ Fontsere-latesies, op. cit., p. 168. 
se sigui cas molt desastrat dintre la Esglea de madona sancta Maria de la Mar, la qual com lo propdit terratremol se segui era plena de poble molts dels quals volgueren exir per cascuns dels portals dela dita esglea. E al eixir del portal maior plach a nostre senyor que la o la qual ere sobre lo dit portal se desvia per lo dit terratremol e caygueren ne diverses pedres, e morihen hi be XXV persones entre homens dones e infants, los quals al exint del dit portal foren ferits per les dites pedres, ultra los quals ni moriren alguns offegats e premuts com per cuyta dexir se lençassen o cayguessen los uns sobre los altres ${ }^{31}$.

De tota manera, l'estrall de Santa Maria fou notable i causà tal impressió que hom en parlà arreu i durant molt de temps. El 4 de febrer, dos dies després de l'accident, Bertran de Tamarit, correu de la ciutat de Barcelona, rebé l'ordre dels honorables Consellers d'anar als monestirs d'Scala Dei, Poblet i Montserrat per demanar als monjos que «facen oracio a nostre senyor Deu quens perdo (e) ens leu per la sua infinida misericordia la plaga del terratremoln ${ }^{32}$.

La nota del ms. 988 de Montserrat és de la mà d'un barceloni no molt allunyat dels fets, si no contemporani. L'enquadernació del còdex és original, del mateix segle xv, poc posterior, per tant, a l'any 1482 , data del darrer colofó que porta el manuscrit. La nota sobre els sismes en qüestió pot haver estat escrita un cop enquadernat el volum, encara que no necessàriament; podria ser que ja existís quan la carta emprada per protegir la tapa - és en el dors en blanc d'aquesta carta que fou anotat el text que hem transcrit i comentat- fou enganxada a l'interior de la coberta posterior. Però si us mireu el còdex probablemente creureu més versemblant la primera opinió, o sigui, que la nota sobre el moviment sismic de tanta ressonància fou escrita un cop enquadernat el volum.

31 Fontseré-Iglésies, op. cit., p. 166.

32 Manual de Novells Ardits, 1, p. 258. Sobre la reacció religiosa davant el pànic que causaven els terratrèmols, vegeu J. RuBıo, «Documents sobre els terratrèmols de 1427-28 a terres de Girona», dins Miscel-lània Fontseré, Barcelona 1961, pp. 357-375, particularment les pp. 358-361. 
Sigui com sigui, el nostre text és un testimoniatge més de la profunda impressió que deixaren els terratrèmols dels anys 1427 i 1428. És un text que, per breu que sigui, afegeix algun detall a les coses que ja sabíem i precisa o complementa les notícies històriques conservades. És, al mateix temps, un document interessant en l'aspecte filològic. 